\title{
Nano-Ag inhibiting action potential independent glutamatergic synaptic transmission but increasing excitability in rat CA1 pyramidal neurons
}

\author{
ZHAOWEI LIU ${ }^{1}$, TAO ZHANG ${ }^{2}$, GUOGANG REN³ ${ }^{3}$ \& ZHUO YANG ${ }^{1}$ \\ ${ }^{1}$ College of Medicine, Key Laboratory of Bioactive Materials, Ministry of Education, Nankai University, Tianjin, ${ }^{2}$ College \\ of Life Science, Nankai University, Tianjin, P. R. China, and ${ }^{3}$ Science and Technology Research Institute, University of \\ Hertfordshire, Hatfield, Herts, UK
}

(Received 1 April 2010; accepted 21 April 2011)

\begin{abstract}
The aim of this study was to investigate the actions of silver nanoparticles (nano-Ag) on glutamatergic synaptic transmission and excitability in hippocampal CA1 pyramidal neurons with whole cell patch technique. The amplitude of miniature excitatory postsynaptic currents (mEPSCs) was inhibited by silver nano-particles (nano-Ag) $\left(10^{-5} \mathrm{~g} / \mathrm{ml}\right.$ and $10^{-4} \mathrm{~g} / \mathrm{ml}$ ), but the amplitude and frequency of spontaneous excitatory postsynaptic currents (sEPSCs) were increased by nano-Ag treatment $\left(10^{-5} \mathrm{~g} / \mathrm{ml}\right.$ and $\left.10^{-4} \mathrm{~g} / \mathrm{ml}\right)$. Furthermore, nano-Ag $\left(10^{-5} \mathrm{~g} / \mathrm{ml}\right.$ and $\left.10^{-4} \mathrm{~g} / \mathrm{ml}\right)$ increased the spontaneous network activity. These results provide further insights into the underlying mechanisms responsible for the effects of nano-Ag on central nervous system (CNS).
\end{abstract}

Keywords: Nano-Ag, neurons, mEPSCs, sEPSCs, spontaneous action potential

\section{Introduction}

Nanomaterials, which are functionally defined as having a single-dimensional feature within the range of 1-100 nm, have been used to create unique devices at the nanoscale level possessing novel physical and chemical functional properties (Ahlbom et al. 2008). Nano-sized materials are now being used in medicine, biotechnology, energy, and environmental technology. Silver nanoparticles (nano-Ag) can be applied to a wide range of healthcare products, such as broadspectrum antimicrobial agents (Kim et al. 2009), biosensors (Sun et al. 2009) and wound dressing (Chen et al. 2006; Muangman et al. 2006). In daily life, consumers may have products containing nanoAg, such as washing machines, ink and clothing (Lee et al. 2007; Vigneshwaran et al. 2007).

According to Panyala et al. (2008), silver can enter through the blood-brain barrier (BBB) and accumulate in different brain regions (Rungby and Danscher 1983). It is known that the biological half-life of silver is longer in the central nervous system (CNS) than that in other organs (Panyala et al. 2008), which suggests silver could have significant physiological actions or pathological consequences to the brain.
Nanoparticles have potential effects on human health since they can pass through biological membranes (Brooking et al. 2001).

Glutamate is rapidly released from presynaptic terminals of neurons and exerts its action on glutamate receptors. The properties of the synaptic currents that are mediated by glutamate receptors are key players in synaptic information efficacy and cell excitability, and changes in these currents will impact upon neuronal network activity in both physiological and pathophysiological conditions. In this study, we examined the effects of nano-Ag on properties of glutamatergic synaptic transmission in vitro.

\section{Materials and methods}

\section{Slice preparation}

Male Wistar rats on postnatal days 14-18 were bred in the Experimental Animal Center, Chinese Academy of Medical Sciences. The experiments were conducted in accordance with the guidelines of the Medical Experimental Animal Administrative Committee of Nation. Horizontal slices that included the entire

Correspondence: Prof. Zhuo Yang, PhD, Professor in Neuroscience, Medical School, University of Nankai, TianJin WeiJin Road 94\#, 300071, P. R. China. Tel: +8622 23504364. E-mail: zhuoyang@nankai.edu.cn 
hippocampus and subiculum (400 $\mu \mathrm{m}$ in thickness) were prepared with a vibratome (VT1000M/E, Leica, Germany) and were incubated in artificial cerebrospinal fluid (ACSF) containing (in $\mathrm{mM}$ ): $125 \mathrm{NaCl}$, $25 \mathrm{NaHCO}_{3}, 1.25 \mathrm{KCl}, 1.25 \mathrm{KH}_{2} \mathrm{PO}_{4}, 1.5 \mathrm{MgCl}_{2}$, $2.0 \mathrm{CaCl}_{2}, 16$ glucose. The standard pipette solution for miniature excitatory postsynaptic currents (mEPSCs) or spontaneous excitatory postsynaptic currents (sEPSCs) was (in $\mathrm{mM}$ ): $\mathrm{CsCl} 140, \mathrm{MgCl}_{2}$ 2, Hepes 10, EGTA 10, Mg-ATP 2, buffered to $\mathrm{pH}$ 7.2 with $\mathrm{CsOH}$. The standard pipette solution for

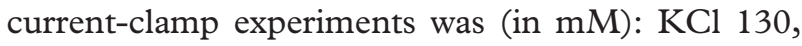
$\mathrm{CaCl}_{2} 1, \mathrm{MgCl}_{2}$ 2, EGTA 10, Hepes 10, Mg-ATP 2, buffered to $\mathrm{pH} 7.2$ with $\mathrm{KOH}$. Bicuculline $(40 \mu \mathrm{M})$ was used in order to block the inhibitory transmission. For mEPSC recording, Tetrodotoxin (TTX) $(1 \mu \mathrm{M})$ was added to block spontaneous action potentials.

TTX was purchased from the Research Institute of the Aquatic Products of Hebei. EGTA, Mg-ATP, bicuculline were purchased from Sigma-Aldrich. Slices were maintained in ACSF for at least $1 \mathrm{~h}$ before moved into the recording chamber. During recordings, the slices were kept submerged in a chamber perfused with ACSF. In the experiments, the ACSF was saturated with $95 \% \mathrm{O}_{2}$ and $5 \% \mathrm{CO}_{2}$.

\section{Nano-Ag particles and solutions}

Nanoparticles of Ag were compounded at Queen Mary University of London, UK, using the raw materials originally obtained from Research Institute of Science \& Technology (STRI), University of Hertfordshire, Herts, UK. The process variables can be controlled to manufacture nano-materials with particular specifications of high purity and well-controlled mean particle size. The particular plasma forming process for producing Ag nanoparticles involves vaporizing feedstock micro-scaled Ag material in a very high temperature (over $10,000^{\circ} \mathrm{C}$ ) plasma stream, and then controlling a rapid cooling process by using $\mathrm{Ar}$ or $\mathrm{He}$ for condensing the vaporized $\mathrm{Ag}$ atoms in down-stream to yield a fine and pure Ag nanoparticle powder, as shown in Figure 1.

Microstructure of nano-Ag was showed using a transmission electron microscope (TEM, Tecnai G2 20 S-TWIN, FEI, USA). The particle sizes of nanoAg suspension $\left(10^{-5} \mathrm{~g} / \mathrm{ml}\right)$ in ACSF were characterized by dynamic light scattering (DLS) using a ZetaPALS + BI-90Plus (Brookhaven Instruments Corp., USA) at a wavelength of $659 \mathrm{~nm}$. The scattering angle was fixed at $90^{\circ}$. Stock solution $\left(10^{-3} \mathrm{~g} / \mathrm{ml}\right)$ of nano$\mathrm{Ag}$ was prepared in Milli-Q water and dispersed by ultrasonic vibration for $20 \mathrm{~min}$. Its suspension was stirred on vortex agitator before every use.

In order to exclude the impact of vehicle, the data in control group were obtained by adding ACSF into extracellular solution using drug application system once currents become stabilized. Final concentrations of $10^{-4} \mathrm{~g} / \mathrm{ml}, 10^{-5} \mathrm{~g} / \mathrm{ml}$ or $10^{-6} \mathrm{~g} / \mathrm{ml}$ nano-Ag suspension were added on the same neuron after $5 \mathrm{~min}$ recording as control. The nano-Ag deposited around the recording cell and played a direct or indirect role on cell.

In order to study the role of nano-Ag is reversible or not, the slices were washed with ACSF (containing $40 \mu \mathrm{M}$ bicuculline and $1 \mu \mathrm{M}$ TTX) by a perfusion system for $5 \mathrm{~min}$ at $3 \sim 4 \mathrm{ml} / \mathrm{min}$ once the recordings were completed.

To investigate the effect of different concentrations of $\mathrm{Ag}$ ions, particles of nano- $\mathrm{Ag}$ in stock solution $\left(10^{-3} \mathrm{~g} / \mathrm{ml}\right)$ were diluted into ACSF to the working concentrations. The concentration of $\mathrm{Ag}$ ions in supernatants of the nanoparticle suspensions in ACSF was determined by an inductively coupled plasma optical emission spectrometry (ICP-OES, ICP-9000 (N + M), Thermo Jarrell-Ash Corp.

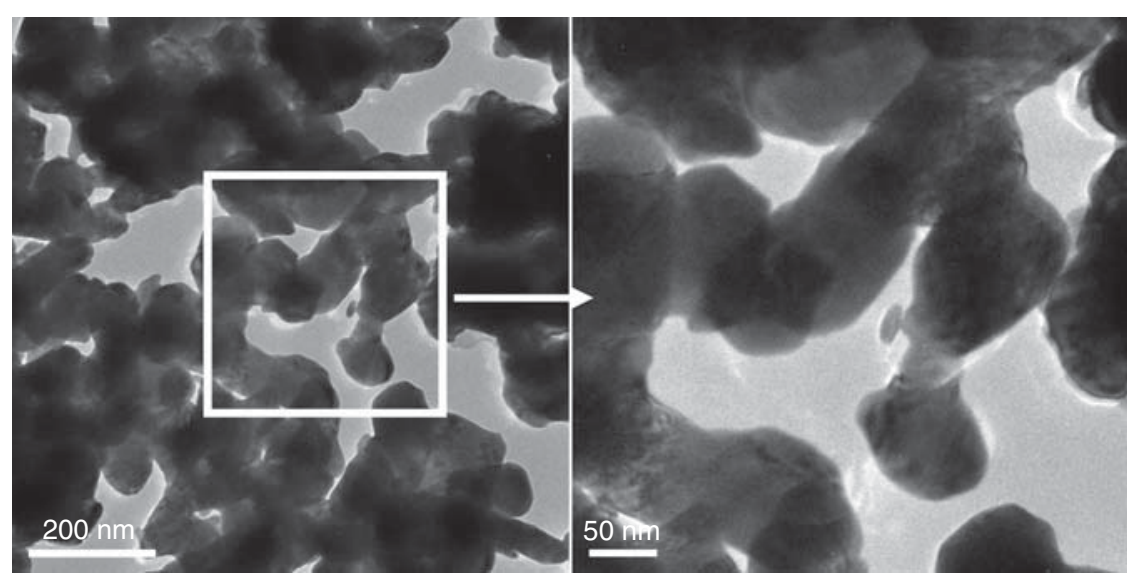

Figure 1. TEM micrographs of (A) nano-Ag particles (scale bar, $200 \mathrm{~nm}$ ) and (B) a higher resolution image (scale bar, $50 \mathrm{~nm}$ ). 
USA) after centrifugation at $13,000 \mathrm{rpm}$, for $30 \mathrm{~min}$ and filtration (100 $\mathrm{nm}$ filter).

\section{Electrophysiological recordings}

For whole-cell recording, slices were transferred to a recording chamber ( $1 \mathrm{ml}$ volume) placed on the stage of an upright infrared differential interference contrast microscopy (BX51WI, Olympus). Hippocampal CA1 neurons were visualized on a television monitor connected to a low light sensitive CCD camera (DVC-710 Cooled Camera). Conventional patch-clamp techniques were used in the present research. Signals were filtered at $5 \mathrm{kHz}$ and digitized at a sampling rate of $2 \mathrm{kHz}$. The series resistance was compensated at least $60 \%$. Leakage and capacitive currents were subtracted on-line using a $\mathrm{P} / 4$ subtraction procedure.

All mEPSCs and sEPSCs were recorded under a holding potential of $-70 \mathrm{mV}$ in voltage-clamp mode. Spontaneous activity was recorded at the neuron's normal resting membrane potential in current-clamp mode.

Data acquisition was performed on computer using EPC10 patch-clamp amplifier (HEKA, Germany). After seal formation and membrane rupture, the cells were allowed to stabilize for 3-5 min before starting pulse protocols.

\section{Data analysis}

The raw data analyses were performed with Clampfit (version 9.2). The values of sEPSCs and mEPSCs were analyzed offline using Clampfit (version 9.2), and the threshold detection was set at $3 \mathrm{pA}$ and all single events were visually inspected.

All values shown in the results section are the mean \pm SEM of the data obtained during $5 \mathrm{~min}$ of drug application or vehicle treatment.

Statistical significance was assessed using a Student's paired $t$-test when there were only two groups involved. In the remaining cases the results were statistically analyzed using one-way ANOVA followed Tukey's multiple comparison. All data analyses were performed using the software SPSS 11.5.

\section{Results}

\section{Characterizations of nano- $\mathrm{Ag}$}

The morphology of the nano-Ag particles was investigated through TEM (as shown in Figure 1). The particle size distribution had a wide range from 41.9-304.91 nm due to the aggregation, and the hydrodynamic mean diameter was $234.9 \mathrm{~nm}$ by
DLS test. The results of concentrations of Ag ions in nano-Ag suspension are shown in Table I.

The effects of nano- $\mathrm{Ag}$ particles on the frequency and amplitude of $m E P S C s$

The mEPSCs were recorded from neurons in standard external solution with $1 \mu \mathrm{M}$ TTX; therefore the mEPSCs were not action potential-dependent. Examples of raw traces were provided in Figure 2A. Nano-Ag particles were tested on the increasing concentrations $\left(10^{-6}, 10^{-5}\right.$ and $\left.10^{-4} \mathrm{~g} / \mathrm{ml}\right)$. In this study, data were obtained from 5-10 min after nano-Ag particles were exposed to hippocampal CA1 neurons.

Below the original traces (Figure 2A) were the bar graphs of frequency and amplitude (Figure 2B, 2C). The concentration-response results showed that nano-Ag decreased the frequency of mEPSCs only on the concentration of $10^{-4} \mathrm{~g} / \mathrm{ml}(p<0.05$, ANOVA). And the amplitude of mEPSCs was decreased on the concentrations of $10^{-4} \mathrm{~g} / \mathrm{ml}$ and $10^{-5} \mathrm{~g} / \mathrm{ml}(p<0.05$, ANOVA). The observed effects on the mEPSCs were completely irreversible after washout (Figure 2).

The effects of nano-Ag particles on the frequency and amplitude of sEPSCs

We also investigated whether sEPSCs in hippocampal neurons were affected by acute nano-Ag application. Examples of raw traces are provided in Figure 3A. Below the traces were the bar graphs of frequency and amplitude (Figure 3B, 3C). It can be seen that higher concentrations of nano- $\mathrm{Ag}\left(10^{-5}\right.$ and $\left.10^{-6} \mathrm{~g} / \mathrm{ml}\right)$ could induce a significant enhancement of both frequency $(p<0.05$, ANOVA $)$ and amplitude $(p<0.05$, ANOVA) of sEPSCs in a concentration-dependent manner. On the other hand, $10^{-6} \mathrm{~g} / \mathrm{ml}$ nano-Ag was insufficient to cause substantial changes of sEPSCs.

High concentrations of nano- $\mathrm{Ag}$ increasing spontaneous network activity

To demonstrate the functional significance of nano-Ag on basal synaptic function, we measured

Table I. The concentrations of soluble Ag ions in nanoAg suspensions (ACSF, pH 7.4, $n=3$ ).

\begin{tabular}{llll}
\hline & $\begin{array}{c}10^{-4} \mathrm{~g} / \mathrm{ml} \\
\text { nano-Ag }\end{array}$ & $\begin{array}{c}10^{-5} \mathrm{~g} / \mathrm{ml} \\
\text { nano-Ag }\end{array}$ & $\begin{array}{l}10^{-6} \mathrm{~g} / \mathrm{ml} \\
\text { nano-Ag }\end{array}$ \\
\hline $\operatorname{ppm~(mg/l)~}$ & $0.16 \pm 0.04$ & $0.04 \pm 0.01$ & $\leq 0.01$ \\
$\mu \mathrm{M}$ & 1.48 & 0.37 & $\leq 0.09$ \\
\hline
\end{tabular}



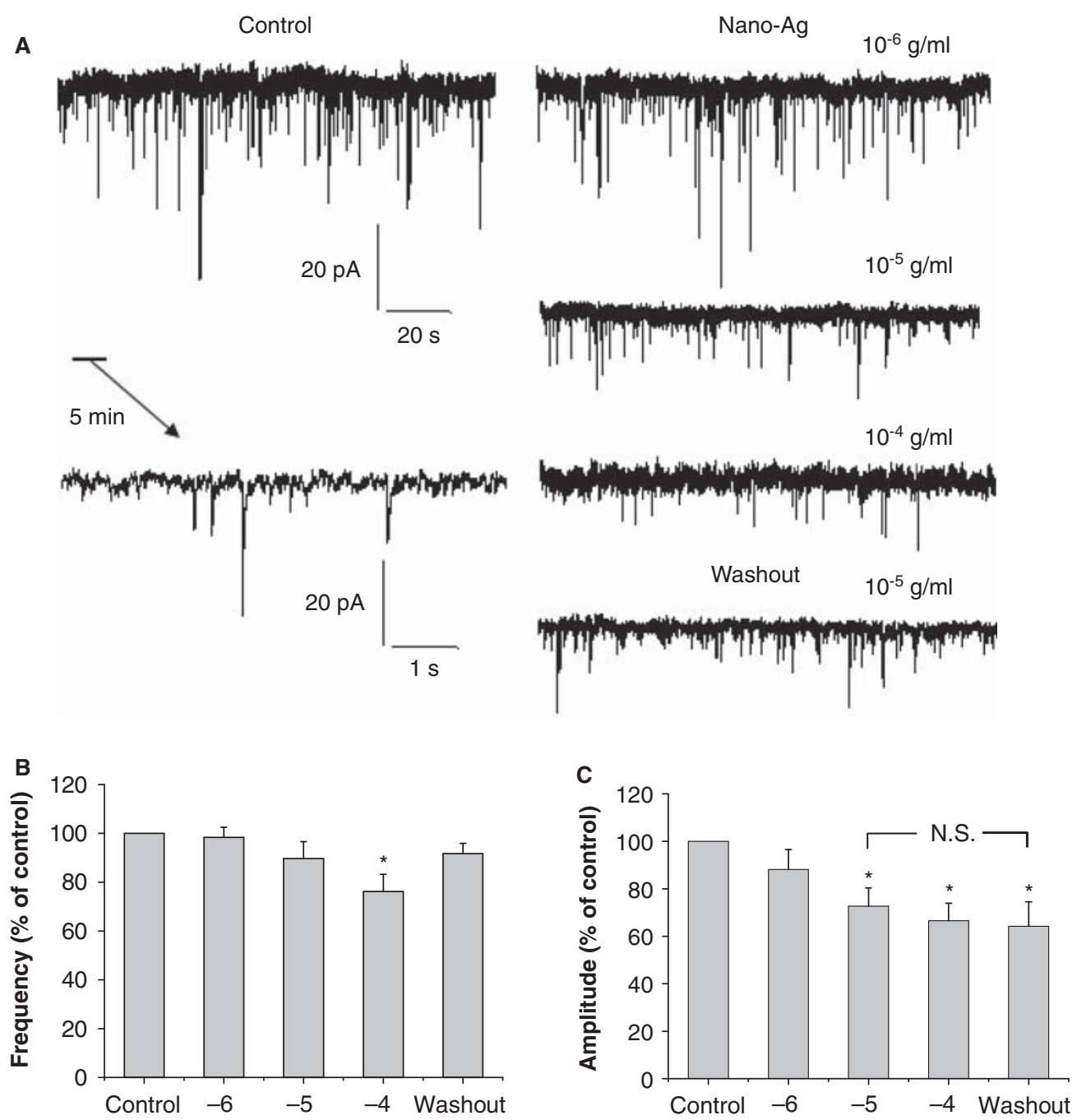

Figure 2. Effects of $10^{-6} \mathrm{~g} / \mathrm{ml}, 10^{-5} \mathrm{~g} / \mathrm{ml}, 10^{-4} \mathrm{~g} / \mathrm{ml}$ nano-Ag and washout after treatment with $10^{-5} \mathrm{~g} / \mathrm{ml}$ nano-Ag on the amplitude and frequency of mEPSCs. (A) All mEPSCs were recorded under a holding potential of $-70 \mathrm{mV}$ in voltage-clamp mode. Bicuculline (40 uM) was used in order to block the inhibitory transmission and TTX (1 uM) was added to block spontaneous action potentials. (B) Statistical summary of nano-Ag induced changes on the frequency of mEPSCs. Data are presented as mean \pm SEM $(p<0.05$, ANOVA). (C) Statistical summary of nano-Ag induced changes on the amplitude of mEPSCs. Data are presented as mean $\pm \operatorname{SEM}(p<0.05$, ANOVA). Significance levels (Tukey's test) are indicated in the figure ${ }^{\star} p<0.05$ vs. controls; N.S., not significant.

spontaneous firing rates of neurons treated with nanoAg in whole cell current-clamp recording. Significant increases in action potential frequency were observed in slices treated with nano- $\mathrm{Ag}\left(10^{-5} \mathrm{~g} / \mathrm{ml}\right.$ and $10^{-4} \mathrm{~g} /$ $\mathrm{ml})(p<0.01$, ANOVA). To investigate the underlying mechanisms of nano-Ag in the changes of spontaneous action potential frequency, we compared the average threshold potential ( $\mathrm{V}$-threshold) and rest membrane potential prior to and during nanoAg application. The V-threshold is the membrane potential to which a membrane must be depolarized to initiate an action potential. Threshold potential was unaffected by nano-Ag $(p>0.05$, ANOVA $)$.
However, nano-Ag only increased the resting membrane potential (RMP) on the concentration of $10^{-4}$ $\mathrm{g} / \mathrm{ml}(p<0.05$, ANOVA) (Figure 4$)$.

In order to investigate whether nano-Ag particles were the molecule responsible for the nano-Agdependent stimulation of spontaneous network activity, the effects of supernatant [centrifugation $(13,000 \mathrm{rpm}$ for $30 \mathrm{~min})$ and filtration (100 nm filter)] of nano-Ag suspensions $\left(10^{-4} \mathrm{~g} / \mathrm{ml}\right)$ in ACSF were tested. The results showed that the supernatant had no effects on the spontaneous action potential firing (control, $2.44 \pm 0.19$; Ag ions, $2.37 \pm 0.11, n=7$, $p>0.05$ paired $t$-test) (Figure 5). 

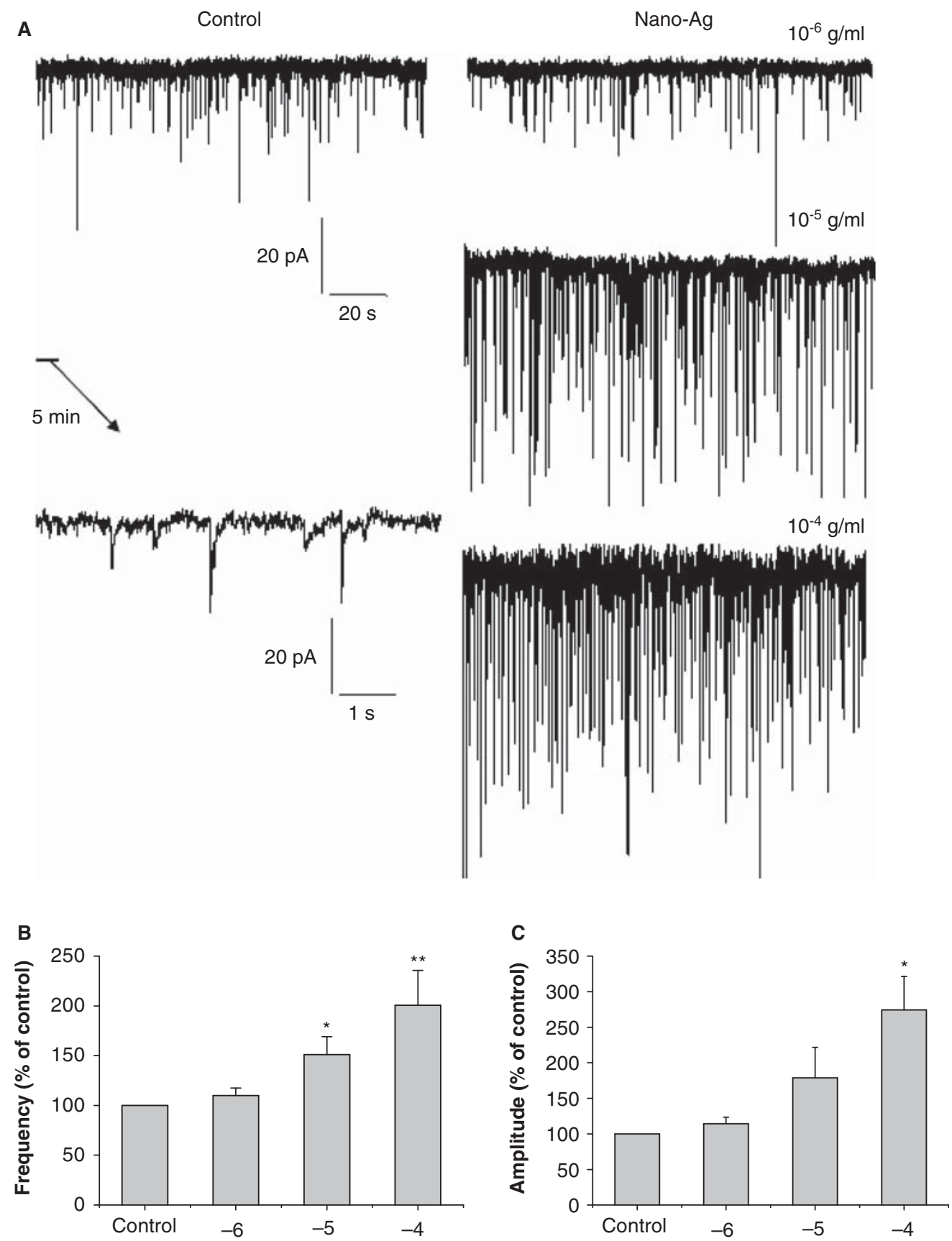

Figure 3. Effects of $10^{-6} \mathrm{~g} / \mathrm{ml}, 10^{-5} \mathrm{~g} / \mathrm{ml}, 10^{-4} \mathrm{~g} / \mathrm{ml}$ nano-Ag on the amplitude and frequency of sEPSCs. (A) All sEPSCs were recorded under a holding potential of $-70 \mathrm{mV}$ in voltage-clamp mode. Bicuculline ( $40 \mathrm{uM}$ ) was used in order to block the inhibitory transmission. (B) Statistical summary of nano-Ag induced changes on the frequency of mEPSCs. Data are presented as mean \pm SEM $(p<0.05$, ANOVA). (C) Statistical summary of nano-Ag induced changes on the amplitude of mEPSCs. Data are presented as mean $\pm \operatorname{SEM}(p<0.05$, ANOVA). Significance levels (Tukey's test) are indicated in the Figure ${ }^{\star} p<0.05{ }^{\star \star} p<0.01$ vs. controls.

\section{Discussion}

Several studies showed that nanoparticles had effects on the electrophysiological properties of excitable cells. Nano-sized quantum dots (Tang et al. 2008) and nano Se (Yuan et al. 2006) impaired voltagegated sodium channel current $\left(I_{\mathrm{Na}}\right)$ in primary cultured hippocampal neuron and rat dorsal root ganglion neuron, respectively. Our previous studies showed that nano particles of $\mathrm{CuO}$ inhibited delayed rectifier potassium current $\left(I_{\mathrm{K}}\right)$ in the concentration of $5 \times 10^{-5} \mathrm{~g} / \mathrm{ml}$ (Xu et al. 2009), while nano$\mathrm{ZnO}\left(10^{-4} \mathrm{~g} / \mathrm{ml}\right)$ increased the amplitudes of transient outward potassium current $\left(I_{\mathrm{A}}\right), \quad I_{\mathrm{K}}$ and $I_{\mathrm{Na}}$ 
A

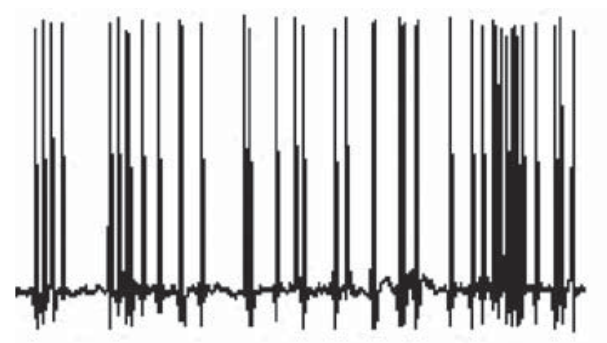

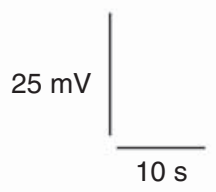

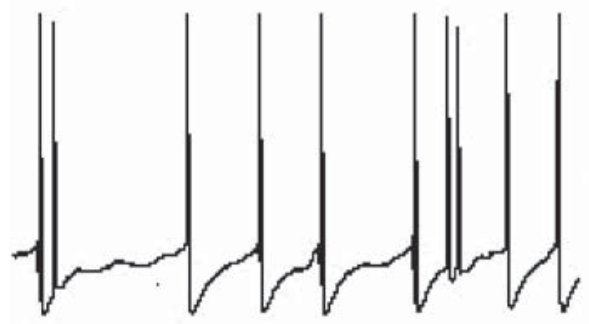

$25 \mathrm{mV}$
Nano-Ag $\quad 10^{-6} \mathrm{~g} / \mathrm{ml}$

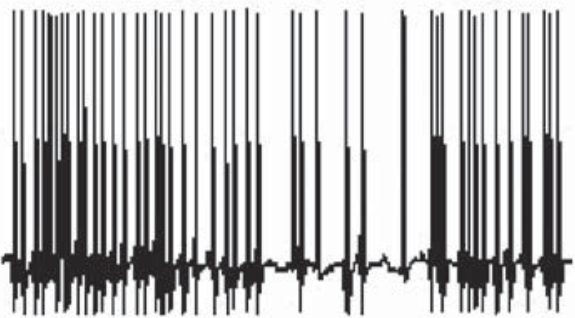

$10^{-5} \mathrm{~g} / \mathrm{ml}$

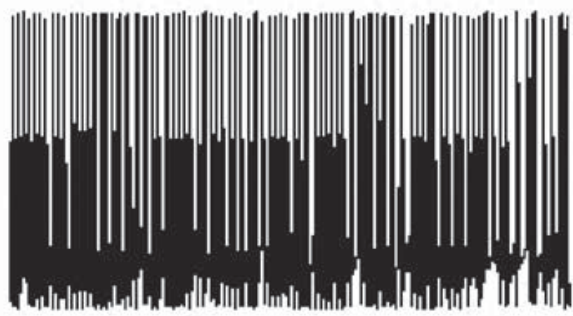

$10^{-4} \mathrm{~g} / \mathrm{ml}$

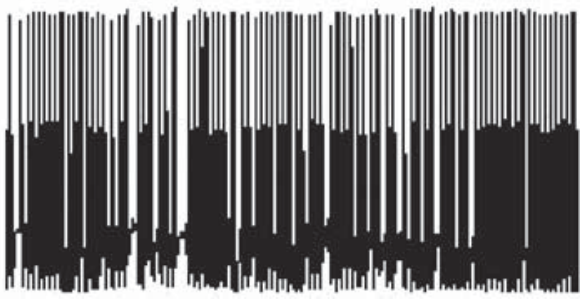

B

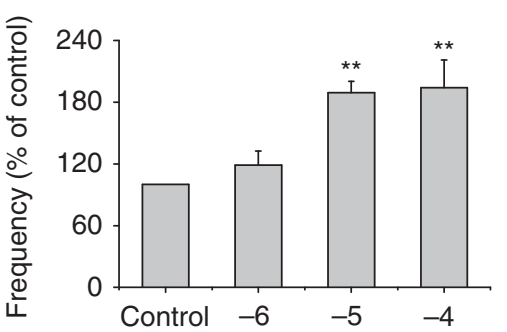

C

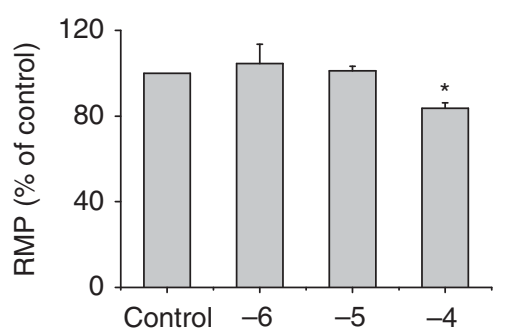

D

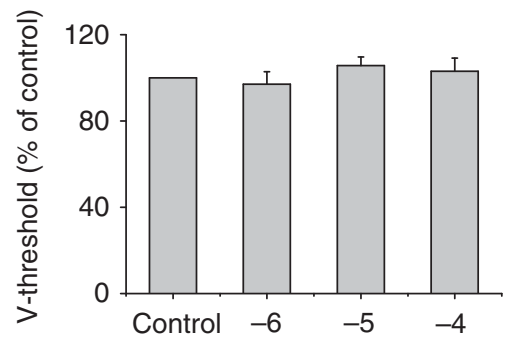

Figure 4. Effects of $10^{-6} \mathrm{~g} / \mathrm{ml}, 10^{-5} \mathrm{~g} / \mathrm{ml}, 10^{-4} \mathrm{~g} / \mathrm{ml}$ nano-Ag on the excitability of CA1 neurons. (A) Spontaneous activity was measured as the number of action potentials discharges at resting membrane potential (RMP). Spontaneous action potentials recorded from a CA1 neuron before and during the application of different concentrations of nano-Ag. (B) Statistical summary of nano-Ag induced changes on the frequency of action potentials. Data are presented as mean \pm SEM $(p<0.01$, ANOVA). (C) Statistical summary of nano-Ag induced changes on the RMP of neurons. Data are presented as mean \pm SEM $(p<0.05$, ANOVA). (D) Bar graph of V-threshold before and during the application of nano-Ag. Data are presented as mean \pm SEM $(p>0.05$, ANOVA). Significance levels (Tukey's test) are indicated in the Figure ${ }^{\star} p<0.05,{ }^{\star \star} p<0.01$ vs. controls.

(Zhao et al. 2009). In the present study, we demonstrated, for the first time, the nano-Ag mediated modulation of synaptic transmission in the CNS.

Postsynaptic actions of nano- $\mathrm{Ag}\left(10^{-5} \mathrm{~g} / \mathrm{ml}\right)$ on mEPSCs

Excitatory postsynaptic currents (EPSCs) in CA1 pyramidal neurons were generated by flow of cations
$\left(\mathrm{Na}^{+}, \mathrm{K}^{+}, \mathrm{Ca}^{2+}\right)$ through glutamate-activated excitatory amino acid receptors. Glutamate is a major excitatory neurotransmitter in the mammalian CNS.

The synaptic plasticity at excitatory synapses is determined by both presynaptically changes in the probability of neuro-transmitter release and postsynaptically modifications in the availability of functional postsynaptic glutamate receptors. It is generally accepted that the changes in frequency of 

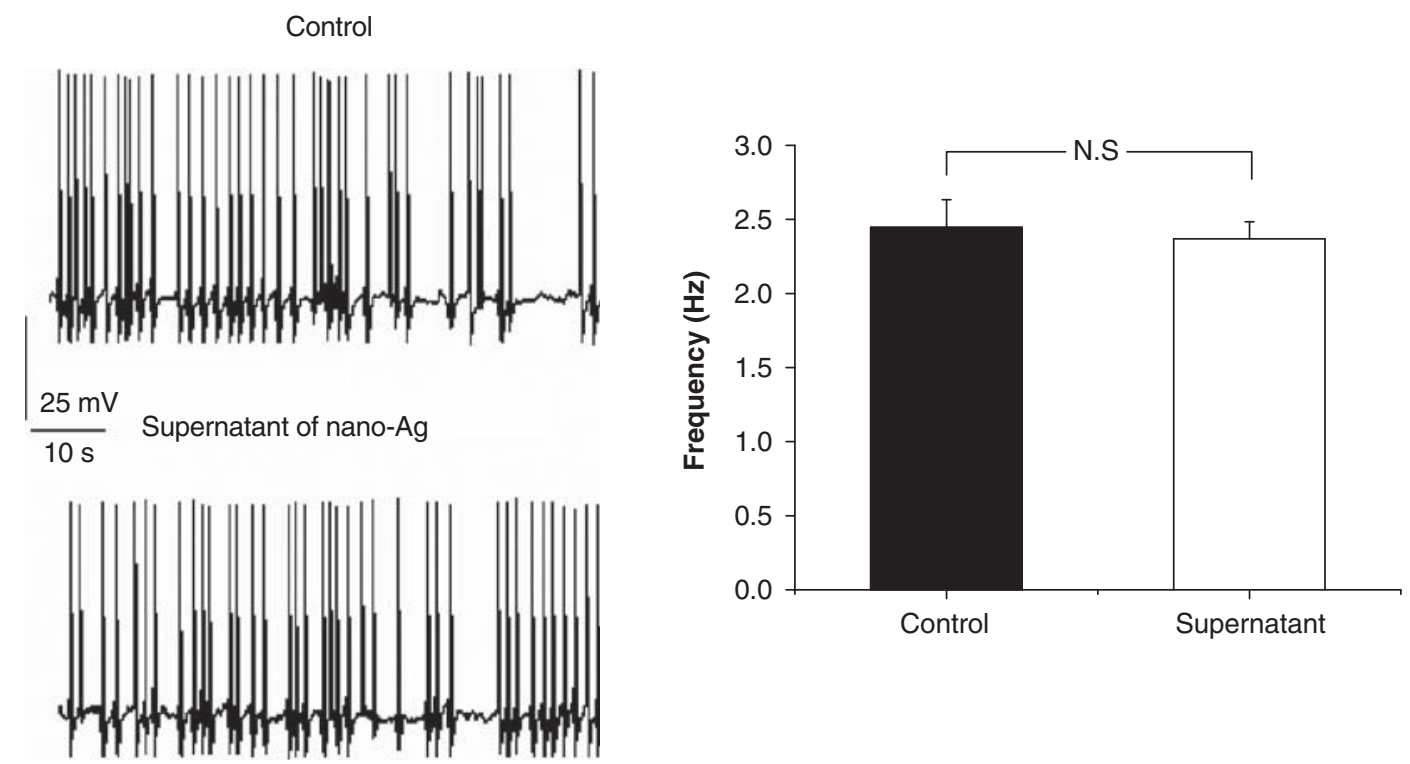

Figure 5. Effects of the supernatant of nano-Ag suspensions $\left(10^{-4} \mathrm{~g} / \mathrm{ml}\right)$ on the excitability of CA1 neurons. N.S., not significant; $(n=7$, $p>0.05$ paired $t$-test).

spontaneous synaptic events usually reflect an altered number of presynaptic neurotransmitter release, and the changes in amplitude indicate postsynaptic alterations in transmitter-receptor interactions. The mEPSCs represent the action potentials that independent the release of neurotransmitters. It is generally accepted that each miniature current is from the spontaneous release of a quantal packet of glutamate from nerve terminals following fusion of synaptic vesicles with the presynaptic membrane.

The experimental results showed that nano$\mathrm{Ag}\left(10^{-6} \mathrm{~g} / \mathrm{ml}\right)$ had no significant effects on synaptic transmission in the neurons in CA1 area. Thus, the concentration of $10^{-5} \mathrm{~g} / \mathrm{ml}$ employed in the present experiments may be the lowest effective concentration. In our study, the mEPSCs frequency remained unaffected by treatment with nano-Ag of the concentration of $10^{-5} \mathrm{~g} / \mathrm{ml}$, which indicated that nano$\mathrm{Ag}\left(10^{-5} \mathrm{~g} / \mathrm{ml}\right)$ did not act on presynaptic glutamate release. However, nano-Ag decreased the amplitude of mEPSCs, which suggested nano-Ag $\left(10^{-5} \mathrm{~g} / \mathrm{ml}\right)$ could substantially interact with postsynaptic glutamate receptors or change postsynaptic receptor sensitivity to glutamate.

At least two different types of cationic channels are gated by this neurotransmitter, the NMDA- and the non-NMDA-type glutamate receptors (GluRs). Evidences showed that both types of receptors were activated at synapses in hippocampal CA1 pyramidal neurons (Pandis et al. 2006; Pilpel et al. 2009).

CA1 pyramidal neurons express high levels of GluRs (1-3) subunits, whereas NMDA receptors (NMDARs) are composed of GluR epsilon (NR2 subunits) assembled with at least one GluR zeta 1 (NR1 subunit) and AMPA receptors (AMPARs) are composed primarily of GluR1/GluR2 and GluR2/ GluR3 heteromers. The action of nano-Ag on postsynaptic receptors is probably selective for some subtypes of ion channels in hippocampal CA1 neurons. Further experiments are required to elucidate the exact underlying mechanism.

However, higher concentration nano- $\mathrm{Ag}\left(10^{-4} \mathrm{~g} / \mathrm{ml}\right)$ inhibited mEPSCs on both frequency and amplitude. These results suggest that the special effects of nano-Ag on mEPSCs partly dependent on the concentrations of nano-Ag.

Both presynaptic and postsynaptic actions of nano- $\mathrm{Ag}$ on sEPSCs

Sodium channel block, however, is an artificial condition. Under the more natural condition of intact sodium channels, nano-Ag increased the amplitude and frequency of sEPSCs. The effects of nano-Ag on sEPSCs could be both presynaptic and postsynaptic since simultaneous detection of amplitude and frequency changes. Excitable effects of nano-Ag on sEPSCs were probably partly dependent on action potentials or $I_{\mathrm{Na}}$ since they were reversed by TTX.

Work on several types of synapses has demonstrated that action potential can increase the neurotransmitter release by multiple vesicles at the same active zone and presynaptic action potentials are involved in neurotransmitter release onto pyramidal neurons (Wall and Usowicz 1998; Prange and 
Murphy 1999; Wadiche and Jahr 2001). Similar findings have been made at CA1 synapses (Tong and Jahr 1994; Oertner et al. 2002; Conti and Lisman 2003). Furthermore, presynaptic $\mathrm{Ca}^{2+}$ influx through voltage-dependent $\mathrm{Ca}^{2+}$ channels triggers neurotransmitter release and action potential plays a determinant role in the dynamics of presynaptic $\mathrm{Ca}^{2+}$ influx in hippocampal neurons (Qian and Saggau 1999).

In addition to the increase in AMPA, receptor function may be due to the synaptic redistribution of intracellular receptors. Shi et al. (1999) demonstrated the rapid insertion of AMPAR into membrane following synaptic activation that suggested shifts in cellular distribution of AMPAR may regulate synaptic receptor activity. These effects induced by nanoAg could be due to NMDAR, which was also sensitive to glutamate.

The best-known glutamatergic input to CA1 pyramidal neurons is via Schaffer collaterals from CA3 area, and this projection is part of the trisynaptic pathway. Since trisynaptic pathway has long been regarded as the major route of information transfer in the process of memory, the excitatory effects of nano-Ag on sEPSCs might facilitate the memory formation.

\section{Spontaneous action potential firing elevation treatment with nano- $A g$}

The normal output mode of neurons is via bursts of action potentials, such firing pattern would have important implications in CA1 circuit as well as its primary target, area subiculum. The excitability of pyramidal neurons within the hippocampus is regulated by the strength of both excitatory and inhibitory inputs. In the CA1 region, the frequency of spontaneous action potential firing is determined by the summation of glutamatergic EPSPs from Schaffer collaterals and GABAergic inhibitory postsynaptic potentials (IPSPs) (Gulyas et al. 1999; Pouille and Scanziani 2001; Saraga et al. 2008).

In our study, nano-Ag $\left(10^{-5} \mathrm{~g} / \mathrm{ml}\right)$ increased the network activity, but had no effects on the resting membrane potential and the threshold of action potential, therefore our data suggested that the excitatory effects of sEPSCs after treatment with nano-Ag, were likely leading to an even larger deficit in overall network activity, without altering the intrinsic of individual neurons. Alternatively, it is also possible that the changes of GABAergic inhibitory interneurons affect firing output by either feedback or feed forward inhibition. However, nano- $\mathrm{Ag}\left(10^{-4} \mathrm{~g} / \mathrm{ml}\right)$ induced the membrane depolarization, which suggested that
nano-Ag can damage the intrinsic characteristics of neurons on the high concentration.

The excitatory effects of nano-Ag on hippocampal neurons are similar with glutamate, which plays a key role in the pathological process of brain disorders. According to Sun et al. (2001), glutamate induced increase in neuronal excitability in hippocampal neurons.

Nano-Ag particles may be the molecule responsible for the nano-Ag-induced changes

The following observations implicate nanoAg particles could be the molecule responsible for the nano-Ag-induced increase of spontaneous network activity, since the currents were changed only in the presence of nano-Ag particles but not by the supernatant of nano-Ag suspensions.

According to Dart et al. (1998), $\mathrm{Ag}^{+}$blocked murine Kir2.1 channels, which are found extensively in the hippocampus (Miyashita and Kubo 1997; Schroder et al. 2002). It is general to receive that $\mathrm{K}^{+}$channels play a role in the excitability. However, the supernatant of nano-Ag (containing $1.48 \mu \mathrm{M}$ $\mathrm{Ag}^{+}$) had no effects on action potential firing in our study. In fact, Kv3-type channels are the main voltage-gated $\mathrm{K}^{+}$channels contributing to the fast repolarizations and afterhyperpolarizations in hippocampal neurons, which play a key role in the action potential firing. In contrast, the contribution of the slow delayed rectifier $\mathrm{K}^{+}$channels and the A-type $\mathrm{K}^{+}$ channels were minimal. It needs to be emphasized that the slow delayed rectifier component could be attributable to $\mathrm{Kv} 2$ subunits (Martina et al. 1998). That suggested the inhibited effects of $\mathrm{Ag}^{+}$on Kir2,1 channels might not the result in the changes on neuronal excitability.

According to our previous researches, nano$\mathrm{ZnO}$ increased the amplitude of $I_{\mathrm{Na}}$ on hippocampal pyramidal neurons (Zhao et al. 2009). However, nano-Ag induced the decrease on $I_{\mathrm{Na}}$ (Liu et al. 2009). That suggested the results we obtained in this study may not be applied to other nanoparticles.

According to Park et al. (2003), nanotubes blocked $\mathrm{K}^{+}$currents through a pore occlusion mechanism, and that size (0.9-1.3 $\mathrm{nM})$ was important parameters impacting channel interactions. Notably the sizes of Ag nanoparticles used in this study are $~ 100$-fold larger, and the discrepancy may be due to that the pore occlusion mechanism is not the only underlying way for small molecules to affect the function of ion channels. In fact, one possible mechanism postulated to be responsible for nano particle cytotoxicity is free radical formation, particularly reactive oxygen species 
(Choi and Hu 2008; Hsin et al. 2008). In addition, the action of phosphorylation cascades signal system could be involved in the process. Many experiments confirmed that signal systems were involved in the effects on synaptic currents and spike discharge frequency by small molecules on neuron (Faber and Sah 2004; Beaumont et al. 2007; Mohajerani et al. 2007; Olijslagers et al. 2008). However, the detailed mechanisms are still unknown, and further investigations are needed.

The present study is the first to report that nano-Ag particles markedly enhancing excitatory synaptic transmission on a concentration-dependent manner. These results provide further insights into the underlying mechanisms responsible for the effects of nano-Ag on CNS.

Declaration of interest: This work was partly supported by the National Natural Science Foundation of China (31000509 and 31070890) and UK Royal Academy of Engineering on a Major Research Exchanges Award (Ref. 5502). The authors report no conflict of interest. The authors alone are responsible for the content and writing of the paper.

\section{References}

-Ahlbom A, Bridges J, de Seze R, Hillert L, Juutilainen J, Mattsson MO, Neubauer G, Schuz J, Simko M, Bromen K. 2008. Possible effects of electromagnetic fields (EMF) on human health - opinion of the scientific committee on emerging and newly identified health risks (SCENIHR). Toxicology 246:248-250.

- Beaumont V, Thompson SA, Choudhry F, Nuthall H, Glantschnig H, Lipfert L, David GR, Swain CJ, McAllister G, Munoz-Sanjuan I. 2007. Evidence for an enhancement of excitatory transmission in adult CNS by Wnt signaling pathway modulation. Mol Cell Neurosci 35:513-524.

Brooking J, Davis SS, Illum L. 2001. Transport of nanoparticles across the rat nasal mucosa. J Drug Target 9:267-279.

Chen J, Han CM, Lin XW, Tang ZJ, Su SJ. 2006. [Effect of silver nanoparticle dressing on second degree burn wound]. Zhonghua Wai Ke Za Zhi 44:50-52.

-Choi O, Hu Z. 2008. Size dependent and reactive oxygen species related nanosilver toxicity to nitrifying bacteria. Environ Sci Technol 42:4583-4588.

Conti R, Lisman J. 2003. The high variance of AMPA receptor- and NMDA receptor-mediated responses at single hippocampal synapses: Evidence for multiquantal release. Proc Natl Acad Sci USA 100:4885-4890.

-Dart C, Leyland ML, Barrett-Jolley R, Shelton PA, Spencer PJ, Conley EC, Sutcliffe MJ, Stanfield PR. 1998. The dependence of $\mathrm{Ag}^{+}$block of a potassium channel, murine kir2.1, on a cysteine residue in the selectivity filter. J Physiol 511(Pt 1):15-24.

Faber ES, Sah P. 2004. Opioids inhibit lateral amygdala pyramidal neurons by enhancing a dendritic potassium current. J Neurosci 24:3031-3039.

Gulyas AI, Megias M, Emri Z, Freund TF. 1999. Total number and ratio of excitatory and inhibitory synapses converging onto single interneurons of different types in the CA1 area of the rat hippocampus. J Neurosci 19:10082-10097.

-Hsin YH, Chen CF, Huang S, Shih TS, Lai PS, Chueh PJ. 2008. The apoptotic effect of nanosilver is mediated by a ROS- and JNK-dependent mechanism involving the mitochondrial pathway in NIH3T3 cells. Toxicol Lett 179:130-139.

-Kim KJ, Sung WS, Suh BK, Moon SK, Choi JS, Kim JG, Lee DG. 2009. Antifungal activity and mode of action of silver nano-particles on Candida albicans. Biometals 22:235-242.

Lee HY, Park HK, Lee YM, Kim K, Park SB. 2007. A practical procedure for producing silver nanocoated fabric and its antibacterial evaluation for biomedical applications. Chem Commun (Camb) 2959-2961.

Liu Z, Ren G, Zhang T, Yang Z. 2009. Action potential changes associated with the inhibitory effects on voltage-gated sodium current of hippocampal CA1 neurons by silver nanoparticles. Toxicology 264:179-184.

- Martina M, Schultz JH, Ehmke H, Monyer H, Jonas P. 1998. Functional and molecular differences between voltage-gated $\mathrm{K}^{+}$ channels of fast-spiking interneurons and pyramidal neurons of rat hippocampus. J Neurosci 18:8111-8125.

- Miyashita T, Kubo Y. 1997. Localization and developmental changes of the expression of two inward rectifying $\mathrm{K}^{+}$-channel proteins in the rat brain. Brain Res 750:251-263.

-Mohajerani MH, Sivakumaran S, Zacchi P, Aguilera P, Cherubini E. 2007. Correlated network activity enhances synaptic efficacy via BDNF and the ERK pathway at immature CA3 CA1 connections in the hippocampus. Proc Natl Acad Sci USA 104:13176-13181.

Muangman P, Chuntrasakul C, Silthram S, Suvanchote S, Benjathanung R, Kittidacha S, Rueksomtawin S. 2006. Comparison of efficacy of $1 \%$ silver sulfadiazine and Acticoat for treatment of partial-thickness burn wounds. J Med Assoc Thai 89:953-958.

-Oertner TG, Sabatini BL, Nimchinsky EA, Svoboda K. 2002. Facilitation at single synapses probed with optical quantal analysis. Nat Neurosci 5:657-664.

-Olijslagers JE, de Kloet ER, Elgersma Y, van Woerden GM, Joels M, Karst H. 2008. Rapid changes in hippocampal CA1 pyramidal cell function via pre- as well as postsynaptic membrane mineralocorticoid receptors. Eur J Neurosci 27:2542-2550.

Pandis C, Sotiriou E, Kouvaras E, Asprodini E, Papatheodoropoulos C, Angelatou F. 2006. Differential expression of NMDA and AMPA receptor subunits in rat dorsal and ventral hippocampus. Neuroscience 140:163-175.

Panyala NR, Pena-Mendez EM, Havel J. 2008. Silver or silver nanoparticles: A hazardous threat to the environment and human health? J Appl Biomed 13.

Park KH, Chhowalla M, Iqbal Z, Sesti F. 2003. Single-walled carbon nanotubes are a new class of ion channel blockers. J Biol Chem 278:50212-50216.

-Pilpel Y, Kolleker A, Berberich S, Ginger M, Frick A, Mientjes E, Oostra BA, Seeburg PH. 2009. Synaptic ionotropic glutamate receptors and plasticity are developmentally altered in the CA1 field of Fmr1 knockout mice. J Physiol 587:787-804.

Pouille F, Scanziani M. 2001. Enforcement of temporal fidelity in pyramidal cells by somatic feed-forward inhibition. Science 293:1159-1163.

Prange O, Murphy TH. 1999. Analysis of multiquantal transmitter release from single cultured cortical neuron terminals. J Neurophysiol 81:1810-1817.

Qian J, Saggau P. 1999. Modulation of transmitter release by action potential duration at the hippocampal CA3-CA1 synapse. J Neurophysiol 81:288-298. 
Rungby J, Danscher G. 1983. Localization of exogenous silver in brain and spinal cord of silver exposed rats. Acta Neuropathol 60:92-98.

-Saraga F, Balena T, Wolansky T, Dickson CT, Woodin MA. 2008. Inhibitory synaptic plasticity regulates pyramidal neuron spiking in the rodent hippocampus. Neuroscience 155:64-75.

-Schroder W, Seifert G, Huttmann K, Hinterkeuser S, Steinhauser C. 2002. AMPA receptor-mediated modulation of inward rectifier $\mathrm{K}^{+}$channels in astrocytes of mouse hippocampus. Mol Cell Neurosci 19:447-458.

- Shi SH, Hayashi Y, Petralia RS, Zaman SH, Wenthold RJ, Svoboda K, Malinow R. 1999. Rapid spine delivery and redistribution of AMPA receptors after synaptic NMDA receptor activation. Science 284:1811-1816.

-Sun DA, Sombati S, DeLorenzo RJ. 2001. Glutamate injury-induced epileptogenesis in hippocampal neurons: An in vitro model of stroke-induced 'epilepsy'. Stroke 32:2344-2350.

- Sun H, Choy TS, Zhu DR, Yam WC, Fung YS. 2009. Nano-silver-modified PQC/DNA biosensor for detecting $E$. coli in environmental water. Biosens Bioelectron 24:1405-1410.

Tang M, Xing T, Zeng J, Wang H, Li C, Yin S, Yan D, Deng H, Liu J, Wang M, Chen J, Ruan DY. 2008. Unmodified CdSe quantum dots induce elevation of cytoplasmic calcium levels and impairment of functional properties of sodium channels in rat primary cultured hippocampal neurons. Environ Health Perspect 116:915-922.

Tong G, Jahr CE. 1994. Multivesicular release from excitatory synapses of cultured hippocampal neurons. Neuron 12:51-59.

-Vigneshwaran N, Kathe AA, Varadarajan PV, Nachane RP, Balasubramanya RH. 2007. Functional finishing of cotton fabrics using silver nanoparticles. J Nanosci Nanotechnol 7:1893-1897.

Wadiche JI, Jahr CE. 2001. Multivesicular release at climbing fiber-Purkinje cell synapses. Neuron 32:301-313.

Wall MJ, Usowicz MM. 1998. Development of the quantal properties of evoked and spontaneous synaptic currents at a brain synapse. Nat Neurosci 1:675-682.

Xu LJ, Zhao JX, Zhang T, Ren GG, Yang Z. 2009. In vitro study on influence of nano particles of $\mathrm{CuO}$ on $\mathrm{CA} 1$ pyramidal neurons of rat hippocampus potassium currents. Environ Toxicol 24:211-217.

-Yuan H, Lin J, Lan T. 2006. Effects of nano red elemental selenium on sodium currents in rat dorsal root ganglion neurons. Conf Proc IEEE Eng Med Biol Soc 1:896-899.

Zhao J, Xu L, Zhang T, Ren G, Yang Z. 2009. Influences of nanoparticle zinc oxide on acutely isolated rat hippocampal CA3 pyramidal neurons. Neurotoxicology 30:220-230. 